\title{
O labirinto sem saída. Gonçalo M. Tavares e W. G. Sebald
}

\author{
Pedro Eiras \\ Universidade do Porto - ILC
}

Resumo: Em Uma Menina Está Perdida no seu Século à Procura do Pai, de Gonçalo M. Tavares, duas personagens perdem-se nos corredores de um hotel cujos quartos têm nomes de campos de concentração. Em Austerlitz, de W. G. Sebald, uma personagem procura os vestígios do seu passado, regressando aos locais da sua infância. Que trauma obriga a repetir, vezes sem conta, o labirinto da memória, conferindo à experiência um sentido tardio e trágico?

Palavras-chave: Gonçalo M. Tavares, Uma Menina Está Perdida no seu Século à Procura do Pai, W. G. Sebald, Austerlitz, labirinto, campos de concentração, trauma

Résumé: Dans Uma Menina Está Perdida no seu Século à Procura do Pai, de Gonçalo M. Tavares, deux personnages se perdent dans les couloirs d'un hôtel dont les chambres portent des noms de camps de concentration. Dans Austerlitz, de W. G. Sebald, un personnage cherche les vestiges de son passé en retournant aux lieux de son enfance. Quel trauma peut bien forcer à répéter, à maintes reprises, le labyrinthe de la mémoire en attribuant à l'expérience un sens différé et tragique?

Mots-clé: Gonçalo M. Tavares, Uma Menina Está Perdida no seu Século à Procura do Pai, W. G. Sebald, Austerlitz, labyrinthe, camps de concentration, trauma 
Tentou perguntar a si mesma de onde viria aquela absurda fidelidade ao horror, mas descobriu que não tinha respostas. Entendia apenas que nada é mais forte que esse instinto de voltarmos onde nos fizeram em pedaços, e de repetir esse instante ao longo dos anos.

Alessandro Baricco, Sem Sangue

Existe um labirinto particularmente inquietante a meio do romance Uma Menina Está Perdida no seu Século à Procura do Pai, de Gonçalo M. Tavares.

Existe, claro, uma menina perdida: Hanna, que tem trissomia 21 e que provavelmente esteve internada numa instituição terapêutica, a avaliar pelas fichas de exercícios e objectivos que traz consigo. Personagem quase inacessível, por vezes parece que Hanna ironiza com a sua própria doença (Tavares 2014: 35), ou que aceita o mundo numa experiência mística (36), capaz de, como Moisés, “separar as águas” (47). Existe também Marius, de quem quase nada saberemos; como um bom samaritano, decide ajudar Hanna a encontrar o pai, mas também confessa, elipticamente: "não sou santo" (34). De qualquer modo, e mesmo que seja por via negativa, mística e santidade constituem um horizonte que define as personagens. Existe ainda, por fim, uma pista obscura:

- Onde podemos procurar o teu pai?

- Blim - respondeu Hanna.

- O teu pai está em Berlim? É de Berlim?

- Belim - respondeu Hanna. (22)

Eis então o primeiro labirinto: Berlim no século XX, ou XXI (não sabemos em que data ao certo acontece esta história). Mas nem sequer é seguro que Hanna tenha querido dizer "Berlim", e a procura pode estar equivocada desde uma palavra imperfeitamente 
pronunciada. Seja como for, Marius e Hanna seguirão este único fio de Ariadne.

Viajam até Berlim e instalam-se num hotel. Quando pede um quarto, Marius percebe, com horror, que os quartos não são designados por números, mas por nomes. Na verdade, nomes de campos de concentração da Segunda Guerra Mundial: Auschwitz, Treblinka, Dachau, Mauthausen-Gusen. Pergunta à dona do hotel: "Porque fazem isto?”, e Raffaela responde: "Porque podemos (...). - Somos judeus." (44). Raffaela não responde que devem ou que precisam de dar esses nomes aos quartos, mas que podem, que têm o poder, a legitimidade ou a autoridade para dar aos quartos nomes de campos de extermínio. Claro que nós, leitores e exegetas, somos livres de questionar a afirmação de Rafaella, suspeitar que se trata menos de poder do que de necessidade ou de uma repetição compulsiva. Mas o carácter elíptico do texto não confirma nem infirma esta especulação.

Entretanto, num capítulo subsequente, Moebius, marido de Rafaella, explica a Marius que a planta do hotel foi desenhada a partir de um mapa da Europa: tal como os campos de concentração no mapa, assim foram dispostos os quartos, respeitando a topografia e a escala. A planta do hotel constitui portanto uma carta dos campos. No fim do capítulo, Moebius une os pontos que representam os campos na planta:

- Vê - disse ele, levantando a cabeça e fixando-me -, obtemos uma forma geométrica. Sabe que esta forma geométrica tem um nome? Não tinha, mas nós demos-lhe um nome, esta forma precisava. Como era possível não dar nome a isto? (...) E era o nome que daríamos ao hotel, se lhe tivéssemos posto um nome. Sabe qual é o nome desta forma geométrica? Quer mesmo saber? (78)

O capítulo termina com esta questão. Não sabemos se Marius quis ou não quis saber o nome da figura. Apenas sabemos que esse nome existe, tem de existir: "nós demos-lhe um nome, esta forma precisava. Como era possível não dar nome a isto?". Agora, nenhum poder, mas pura necessidade - ou urgência. E a pergunta “Quer mesmo saber?" indicia que saber esse nome não confere legitimidade nem autoridade, apenas horror.

Mas avancemos ainda um pouco mais. Somente alguns capítulos depois o hotel acabará de revelar-se efectivamente como labirinto. Uma noite, Marius e Hanna chegam tarde, as luzes dos corredores estão apagadas; para se guiarem, apenas podem contar com a 
luz emitida pelas letras metálicas nas portas dos quartos. Perdido no dédalo de corredores, na escuridão iluminada pelos nomes de campos de concentração, Marius começa a ceder a um pânico que teremos de interrogar. Cito, com alguma extensão, o final deste capítulo:

Estávamos já outra vez perdidos e eu decidi que, a partir dali, para não transmitir mais insegurança a Hanna, avançaria sempre, procurando não manifestar qualquer indecisão, como se soubesse já o caminho certo e estivéssemos a andar muito apenas por o caminho ser longo. (...) Começava a ficar aterrado. Imaginei-nos, de súbito, a dormir nos corredores. Pensei como seríamos ridicularizados. Sentia a cara vermelhíssima; se houvesse luz suficiente, ver-se-ia o meu rosto corado de vergonha. No nosso lado esquerdo o Treblinka, depois o Majdanek, depois do lado direito, o Belzec. As minhas pernas tremiam, mas ali estava finalmente algo, uns metros à frente, do nosso lado direito, um $\mathrm{A}$ brilhava - o que me pareceu um A enorme, um A gigantesco, e depois um U, um S, o Witz do final. Auschwitz. Senti uma enorme descarga no corpo, como se uma energia agressiva subitamente tivesse caído para que eu a pudesse sacudir. Era uma enorme sensação de alívio; uma alegria. Apetecia-me dar um pequeno urro de contentamento, mas mantive a concentração até ao fim; controlei-me, aproximei a chave da fechadura, rodei-a, e abri a porta do quarto para Hanna entrar. Chegámos, disse.

Por que razão Marius está "aterrado"? Existe uma resposta explícita: "Imaginei-nos, de súbito, a dormir nos corredores. Pensei como seríamos ridicularizados." Porém, de um ponto de vista estritamente racional, não existe aqui verdadeiro motivo para terror, nem uma questão de vida ou de morte; na pior das hipóteses, Marius e Hanna terão de dormir uma noite no chão, sendo resgatados de manhã. Marius poderá ser ridicularizado, considerado incapaz de se orientar, talvez irresponsável, mesmo incapaz de cuidar de Hanna, mas poderá defender-se; continua a não haver razão para o terror. Pelo contrário, o carácter alegórico do texto exige que a resposta esteja noutro lugar.

Quando Marius encontra a porta do quarto, exulta: "Era uma enorme sensação de alívio; uma alegria. Apetecia-me dar um pequeno urro de contentamento" (111). Num primeiro nível de leitura, reconhecemos aqui o alívio de quem encontra a saída de um labirinto; porém, chocantemente, Marius está "aliviado", "alegre”, "contente” por encontrar um quarto chamado Auschwitz, num hotel desenhado de acordo com o mapa dos campos. 
Numa formulação literal e obscena: Marius está contente por ter chegado a Auschwitz.

Como compreender este contentamento? É possível, por exemplo, que Marius se sinta em dívida perante os donos do hotel ou os outros inquilinos, aqueles que escolheram, por uma qualquer razão secreta, um determinado quarto; penso em particular no velho que mora, permanentemente, no quarto Terezin. Talvez Marius sinta que, entre sobreviventes e testemunhas, também ele deve assumir o horror dos campos; talvez sinta que a única obscenidade é ser desprovido de memórias do horror, de uma narrativa, ser indemne onde os outros foram marcados para sempre. Nesse sentido, o hotel é um labirinto porque Marius apenas pode ser um inquilino efémero, quase um intruso, no lugar que para os outros clientes é um lugar dolorosamente próprio.

Na verdade, não sabemos quase nada do passado de Marius. Nem sequer se é judeu, marxista, cigano, homossexual - vítimas imediatas dos campos de concentração -, se é um sobrevivente, um filho ou um neto de um sobrevivente; não sabemos que histórias de terror o constituem, ou se ele se sente realmente como um intruso no hotel sem nome de Moebius e Raffaela. Sabemos, por outro lado, que os campos de concentração executaram sumariamente centenas de milhares de pessoas com deficiências cognitivas; mesmo que Hanna seja demasiado jovem para ter enfrentado o genocídio nazi, sabemos que ela seria teria sido - uma vítima inevitável. Assim, este episódio revela-se particularmente chocante. Do mesmo modo que um velho sobrevivente quer morar num quarto chamado Terezin, assim o bem-intencionado Marius leva Hanna, uma criança com trissomia 21, até um quarto chamado Auschwitz, nome do campo onde ela teria sido inapelavelmente gaseada.

Talvez possa voltar a descrever esta sequência de comportamentos estranhíssimos, no limiar do inexplicável, recorrendo a um termo clínico que evitei até aqui: o trauma. Segundo a psicanálise (cf. Caruth 1996), o trauma é uma ferida psíquica que tem lugar quando um acontecimento violento ameaça, inesperadamente, um determinado sujeito; após o evento, o sujeito repete a experiência repetidas vezes, através de sonhos, memórias, actos compulsivos, procurando dotá-lo de sentido. 0 ganho psíquico desta repetição consiste em elevar à consciência o fundo inassimilado de uma experiência inquietante, 
insuportável. Deste modo, apenas na repetição a experiência pode ser inteiramente assumida, como defende Cathy Caruth em Unclaimed Experience:

The shock of the mind's relation to the threat of death is thus not the direct experience of the threat, but precisely the missing of this experience, the fact that, not being experienced in time, it has not yet been fully known. (...) The return of the traumatic experience in the dream is not the signal of the direct experience but, rather, of the attempt to overcome the fact that it was not direct, to attempt to master what was never fully grasped in the first place. (1996: 62)

Pelo trauma, afirma Caruth, o sujeito apercebe-se da medida da sua própria ignorância: ele sobreviveu a um perigo de que não pôde ter plena consciência, e apenas a repetição alucinatória permite um “endless attempt to assume one's survival as one’s own” (64).

Tentativa sem fim, obsessiva, de recuperar pela memória ou pelo imaginário uma experiência inassimilável: assim se poderia também descrever o último romance de W. G. Sebald, Austerlitz, publicado em 2001. Neste texto profundamente inquietante, o narrador descreve os seus encontros com um historiador, Jacques Austerlitz, o qual narra, por seu turno, a procura do seu passado: nascido na Chescoslováquia, Austerlitz teria sido levado para Inglaterra em 1939, num Kindertransport, e adoptado por um pregador, nunca mais reencontrando os pais. Décadas mais tarde, Austerlitz dedica-se a uma pesquisa incansável, consultando arquivos, visitando ruínas, dialogando com outros pesquisadores, e perdendose afinal na revisitação melancólica de um tempo perdido.

Nas suas viagens, Austerlitz sente muitas vezes que se encontra em locais onde já esteve, embora não possua nenhuma memória concreta. Apenas ao regressar aos locais ele pode compreender que já ali passou, outrora. Como no trauma, é a repetição que permite a consciência presente da experiência do passado; nesse sentido, é apenas ao repeti-la que essa experiência finalmente se concretiza. Na verdade, Austerlitz está tão atento a este regresso latente dos factos que qualquer resto do passado se revela imediatamente como acontecimento presente, acontecimento que não pára de regressar e de se cumprir. Esta fusão alucinatória dos tempos, pela qual Austerlitz pertence em simultâneo a um passado 
impossível e a um presente diferido, sustenta todo o universo fantasmagórico de Sebald. Eis apenas um exemplo, entre tantos:

li pela enésima vez (...) que em meados de Dezembro de 1942, portanto, precisamente quando Agáta [isto é, a mãe de Austerlitz] chegou a Terezín, estavam encerradas no gueto, numa construção edificada numa superfície de um quilómetro quadrado, umas sessenta mil pessoas, e momentos depois, no exterior, na praça deserta, tive a nítida impressão de que afinal nunca os tinham levado embora, viviam ainda empilhados naquelas casas, nas caves e nos sótãos, subiam e desciam incansavelmente escadas, olhavam pelas janelas, deslocavam-se em grande número pelas ruas e vielas e, numa assembleia muda, enchiam até o espaço ocupado pelo ar tracejado a cinzento pela chuva fina. (2004: 186-187)

Não posso analisar aqui, com a lentidão necessária, esta página tão dolorosa: compreender a especificidade deste pretérito imperfeito que introduz um cruzamento de tempos reais e impossíveis, estudar os encontros de narrativas - do narrador anónimo a Austerlitz e de Austerlitz aos textos que consulta -, compreender o que existe aqui de desejo, trauma, luto, mortos que ainda estão vivos e vivos que já são mortos. Em breves linhas, apenas posso enfatizar que Austerlitz não esteve em Terezin em Dezembro de 1942; ele somente narra que lê um texto que narra que... Mas neste labirinto de textos e vozes, sabemos que pode haver trauma mesmo sem ter havido presença no lugar da violência. Austerlitz vive, agora, a consciência angustiada de uma experiência que nunca foi a dele mas que se torna dele através da narrativa.

Uma fotografia, como veremos de seguida, pode levar à mesma vivência de um tempo fora dos tempos. 0 narrador transmite a narrativa de Jacques Austerlitz, que transmite as palavras de Vìra, antiga amiga dos pais dele:

Vìra (...) falava do insondável que são as fotografias arrancadas ao esquecimento. Tem-se a impressão, disse ela, de que alguma coisa nelas mexe, como se captássemos gemidos de desespero, des gémissements de désespoir, sugeriu ela, disse Austerlitz, como se as imagens tivessem uma memória própria e se recordassem de nós, os sobreviventes, e a nós recordassem quem fomos e quem foram os outros, os que já não estão connosco. (170) 
Novamente, é difícil fazer justiça a todas as ideias presentes em algumas linhas densíssimas de Sebald. Limito-me a assinalar que também a fotografia permite a consciência de uma experiência; que também a fotografia desfaz o fio do tempo num presente invencível em que os "gemidos de desespero" continuam a soar; mas agora sabemos que a iniciativa não é do sujeito rememorante ou alucinante, é das fotografias, "como se as imagens tivessem uma memória própria", ou como se a fotografia tivesse um inconsciente óptico, nas palavras de Benjamin (1992), um inconsciente recalcado mas latente, traumático.

Por outro lado, se o trauma segundo Cathy Caruth permite que o sujeito assuma a sua própria sobrevivência, a sua realidade como sobrevivente, Vìra diz: é "como se as imagens (...) se recordassem de nós, os sobreviventes, e a nós recordassem quem fomos e quem foram os outros, os que já não estão connosco". A fotografia, como o trauma, é o lugar da consciência da morte evitada, da sobrevida, o lugar em que o sujeito faz o trabalho infinito da percepção da sua sobrevivência. Isto é o que Sebald diz que Austerlitz diz que Vìra diz, mas é também o trabalho do leitor perante as numerosas fotografias dos livros de Sebald. Nessas imagens baças de paisagens desoladas, abandonadas, mortas, também o leitor é convidado a alucinar o regresso dos mortos, daqueles que vivem "ainda empilhados naquelas casas, nas caves e nos sótãos", que enchem "até o espaço ocupado pelo ar tracejado a cinzento pela chuva fina"...

Seria preciso, num ensaio mais longo, desenvolver uma leitura comparatista em torno de Austerlitz e de Uma Menina Está Perdida no seu Século à Procura do Pai. Seria preciso, perante os dois textos, pensar a relação entre história, memória, imaginário, narrativa; a ferida traumática do século XX, a narrativa das vítimas e dos sobreviventes; 0 fascínio do arquivo, dos objectos interrogados pela memória, da própria necessidade de inquirir; o pânico a frio, a obsessão de uma fuga impossível, a ameaça de um regresso do horror. Sintomaticamente, tanto em W. G. Sebald como em Gonçalo M. Tavares existem personagens preocupadas com possuírem apenas os objectos que caibam numa mochila, para poderem fugir a qualquer momento: o velho que mora no quarto Terezin, ou o próprio Austerlitz. A personagem traumatizada é indelevelmente nómada. 
Não poderei realizar essa leitura comparatista neste breve ensaio. Regressarei apenas, uma última vez, ao labirinto do hotel de Uma Menina Está Perdida no seu Século à Procura do Pai. Raffaela afirma que pode dar aos quartos os nomes de campos de concentração; mesmo contra esta afirmação literal do texto, já sugeri que não se trata tanto de um poder quanto de uma necessidade de repetir, traumaticamente, a realidade inassimilável dos campos. Quem sobreviveu a Auschwitz não pode deixar de regressar sempre a Auschwitz, através de sonhos, narrativas, a planta de um hotel, o nome de um quarto.

Mas como regressar a esse campo? Em Écorces, Georges Didi-Huberman descreve a sua ida a Auschwitz-Birkenau em 2011. Encontra aí um lugar transformado em museu de um lugar: Auschwitz evoca Auschwitz, pedagogicamente, introduzindo uma distância em relação ao próprio inassimilável. Nas suas palavras:

Tous les lieux de culture - les bibliothèques, les salles de cinéma, les musées - peuvent contribuer de par le monde à construire une mémoire d'Auschwitz, cela va sans dire. Mais que dire quand Auschwitz doit être oublié dans son lieu même pour se constituer comme un lieu fictif destiné à se souvenir d'Auschwitz? (2011: 25)

De certo modo, o hotel de Moebius e Raffaela, sem carácter pedagógico, sem possuir qualquer objecto de Auschwitz, qualquer ligação ao próprio lugar do campo - a não ser um nome e uma planta (significativa mas críptica) -, e provavelmente por essa mesma pobreza, esse labirinto de escuridão onde só algumas letras brilham, permite regressar a Auschwitz, preservar o trauma na sua resolução impossível.

Não saberemos se Marius é um sobrevivente dos campos; se teve alguma experiência do horror nazi, da qual este hotel fosse agora a tardia tomada de consciência. Na verdade, essa questão é quase escusada, porque, depois de Auschwitz, todos nós - que estamos vivos - somos sobreviventes. E tal como Austerlitz, em W. G. Sebald, vive as experiências dos outros (as experiências das fotografias, das narrativas), assim Marius vive a experiência dos prisioneiros dos campos.

Neste sentido, não existe saída do labirinto do hotel. A única saída é um quarto 
Pedro Eiras

chamado Auschwitz, mas essa saída dá para o nó cego do próprio labirinto. E esse quarto, sabemos, nunca mais poderá ser fechado.

\section{Bibliografia}

Baricco, Alessandro (2004), Sem Sangue, trad. Rosa Freire d'Aguiar, Lisboa, Dom Quixote [2002].

Benjamin, Walter (1992), Sobre Arte, Técnica, Linguagem e Política, trad. Maria Luz Moita, Maria Amélia Cruz e Manuel Alberto, Lisboa, Relógio d’Água, 115-135.

Caruth, Cathy (1996), Unclaimed Experience. Trauma, narrative, and history, Baltimore e Londres, The John Hopkins University Press.

Didi-Huberman, Georges (2011), Écorces, Paris, Minuit.

Sebald, W. G. (2004), Austerlitz, trad. Telma Costa, Lisboa, Teorema [2001].

Tavares, Gonçalo M. (2014), Uma Menina Está Perdida no seu Século à Procura do Pai, Porto, Porto Editora. 
Pedro Eiras é Professor de Literatura Portuguesa na Faculdade de Letras da Universidade do Porto e Investigador do Instituto de Literatura Comparada Margarida Losa. Dedica-se à pesquisa sobre poesia e ficção portuguesa dos séculos XX e XXI, literatura comparada, estudos interartísticos, questões de ética, a representação e o imaginário do fim do mundo. Publicou diversas obras de ensaio: Esquecer Fausto, sobre a fragmentação do sujeito na literatura (2005, Prémio Pen Clube Português de Ensaio); A Moral do Vento, sobre Gonçalo M. Tavares (2006); A Lenta Volúpia de Cair, sobre poesia dos séculos XX e XXI (2007); Boomerang, postais sobre representações literárias da Europa (2009); Tentações, sobre Sade e Raul Brandão (2009); Substâncias Perigosas, crónicas sobre o poder da literatura (2010); Um Certo Pudor Tardio, sobre os «poetas sem qualidades» (2011); Os Ícones de Andrei, sobre Andrei Tarkovsky (2012); A Vida Repercutida (com Luis Maffei), sobre Gastão Cruz (2012); Constelações, ensaios comparatistas (2013); Platão no Rolls-Royce, sobre literatura e técnica (2014); e Alumiação (com fotografias de Susana Paiva), sobre poesia, visão e cegueira (2016). 